\title{
Runs of homozygosity analysis reveals consensus homozygous regions affecting production traits in Chinese Simmental beef cattle
}

Guoyao Zhao ${ }^{\dagger}$, Yuqiang Liu ${ }^{\dagger}$, Qunhao Niư ${ }^{\dagger}$, Xu Zheng, Tianliu Zhang, Zezhao Wang, Lei Xu, Bo Zhu, Xue Gao, Lupei Zhang, Huijiang Gao, Junya Li ${ }^{*}$ and Lingyang $\mathrm{Xu}^{*}$

\begin{abstract}
Background: Genomic regions with a high frequency of runs of homozygosity $(\mathrm{ROH})$ are related to important traits in farm animals. We carried out a comprehensive analysis of $\mathrm{ROH}$ and evaluated their association with production traits using the BovineHD (770 K) SNP array in Chinese Simmental beef cattle.

Results: We detected a total of 116,953 homozygous segments with 2.47Gb across the genome in the studied population. The average number of $\mathrm{ROH}$ per individual was 99.03 and the average length was $117.29 \mathrm{Mb}$. Notably, we detected 42 regions with a frequency of more than 0.2 . We obtained 17 candidate genes related to body size, meat quality, and reproductive traits. Furthermore, using Fisher's exact test, we found 101 regions were associated with production traits by comparing high groups with low groups in terms of production traits. Of those, we identified several significant regions for production traits $(P<0.05)$ by association analysis, within which candidate genes including ECT2, GABRA4, and GABRB1 have been previously reported for those traits in beef cattle.
\end{abstract}

Conclusions: Our study explored ROH patterns and their potential associations with production traits in beef cattle. These results may help to better understand the association between production traits and genome homozygosity and offer valuable insights into managing inbreeding by designing reasonable breeding programs in farm animals.

Keywords: Runs of homozygosity, Production traits, Consensus ROH, Association analysis, Chinese Simmental beef cattle

\footnotetext{
*Correspondence: lijunya@caas.cn; xulingyang@163.com

${ }^{\dagger}$ Guoyao Zhao, Yuqiang Liu and Qunhao Niu are co-first authors.

Key Laboratory of Animal Genetics Breeding and Reproduction, Ministry of

Agriculture and Rural Affairs, Institute of Animal Science, Chinese Academy of Agricultural Sciences, Yuanmingyuan West Road 2\#, Haidian District, 100193 Beijing, China
}

C C The Author(s). 2021 Open Access This article is licensed under a Creative Commons Attribution 4.0 International License, which permits use, sharing, adaptation, distribution and reproduction in any medium or format, as long as you give appropriate credit to the original author(s) and the source, provide a link to the Creative Commons licence, and indicate if changes were made. The images or other third party material in this article are included in the article's Creative Commons licence, unless indicated otherwise in a credit line to the material. If material is not included in the article's Creative Commons licence and your intended use is not permitted by statutory regulation or exceeds the permitted use, you will need to obtain permission directly from the copyright holder. To view a copy of this licence, visit http://creativecommons.org/licenses/by/4.0/. The Creative Commons Public Domain Dedication waiver (http://creativecommons.org/publicdomain/zero/1.0/) applies to the data made available in this article, unless otherwise stated in a credit line to the data. 


\section{Background}

Runs of homozygosity $(\mathrm{ROH})$ is defined as contiguous regions of the genome where an individual is homozygous across sites. $\mathrm{ROH}$ arises when the haplotypes transmitted from the parents are identical and inherited from a common ancestor [1]. Increasing the proportion of homozygous loci and generating homozygous segments can be used to reflect the loss of genetic diversity [2] and the performance of traits in livestock [3].

Many studies revealed the negative impact of high homozygosity on fertility traits including bull semen quality [4], calving rate [5], stillbirths, and dystocia [6]. Therefore, controlling inbreeding in modern breeding programs and maintaining genetic diversity have attracted major attention within breeding schemes [7, 8].

Previous studies have been carried out to explore $\mathrm{ROH}$ and its potential association with diseases in humans [9-12]. Investigation of $\mathrm{ROH}$ in farm animals also suggested their important contributions to complex traits [2]. For instance, a previous study evaluated the association between $\mathrm{ROH}$ and reproduction traits using whole-genome homozygosity mapping and revealed candidate regions affecting bull fertility in US Holstein cattle [13]. Moreover, a recent study identified $\mathrm{ROH}$ that unfavorably affects female fertility and milk production traits in the Finnish Ayrshire population [14].

Allocating $\mathrm{ROH}$ into different classes based on length can be used to separate recent and ancient inbreeding. Long $\mathrm{ROH}$ may reflect recent inbreeding with a very low probability of recombination, while short $\mathrm{ROH}$ may indicate ancient inbreeding [15]. Based on genetic purging theory, ancient inbreeding that occurred from a distant common ancestor is expected to show less unfavorable effect due to purging, whereas recent inbreeding arising from a most recent common ancestor may exhibit larger unfavorable effects [16]. Genome-wide inbreeding depression was observed for milk yield and udder health traits in dairy cattle. For instance, a previous study suggested that the increase in genome-wide homozygosity was associated with a decrease in milk yield [17]. In contrast, another study evaluated the effect of recent and ancient inbreeding on production and fertility traits, and their findings suggested recent genomic inbreeding showed more detrimental inbreeding effects in Canadian Holsteins, while more distant ancient inbreeding may cause favorable effects [18]. However, the relationship between $\mathrm{ROH}$ and economically important traits and the effect of recent and ancient inbreeding on production traits in beef cattle are still not fully explored.

The objectives of this study were to evaluate the homozygous segment pattern at the whole genome level in Chinese Simmental beef cattle and assess the association between ancient homozygous segments and production traits.

\section{Results}

Assessment of runs of homozygosity

In this study, we identified a total of $116,953 \mathrm{ROH}$ with $2.47 \mathrm{~Gb}$ across the genome in 1181 Chinese Simmental beef cattle. We found an average number of $99.03 \mathrm{ROH}$ segments per individual with an average length of 117.29 Mb. Most ROH ( 69.60\%) belong to the short class, ranging from $0.5 \mathrm{Mb}$ to $1 \mathrm{Mb}$, while the large class only occupies a small portion (2.1\%) (Supplement Table $\mathrm{S} 1)$. Moreover, we identified the largest $\mathrm{ROH}$ located on BTA9 $(57,696.85 \mathrm{~kb}$, with 13,143 SNPs), while the shortest $\mathrm{ROH}$ was observed on BTA7 (500.021 kb, with 123 SNPs). In addition, we observed that the number of $\mathrm{ROH}$ varied across autosomes (from 1,187 $\mathrm{ROH}$ on BTA25 to 9,176 ROH on BTA11). The distribution of the total number of $\mathrm{ROH}$ across chromosomes was presented in Fig. 1 A. The distribution of the total length of $\mathrm{ROH}$ across chromosomes was shown in (Supplement Figure S1). We found that the number of $\mathrm{ROH}$ per chromosome generally reflect the chromosome size.

We divided $\mathrm{ROH}$ into three classes: (A) Small (500 $\mathrm{kb}$ to $1 \mathrm{Mb}$ ), (B) Medium (1 Mb to $5 \mathrm{Mb}$ ), and (C) Large $(>5 \mathrm{Mb})$ [19]. The $\mathrm{ROH}$ distributions of total number and length for each class were presented in Fig. 1B. The proportion of $\mathrm{ROH}$ covering the genome with different lengths (thus inferred to be autozygous) varied in our population. Our result showed that the total length of Medium $\mathrm{ROH}$ was larger than Small and Large ROH. Small ROH was found to be predominant in the studied population by their total numbers. Moreover, we observed the total number of $\mathrm{ROH}$ and length of $\mathrm{ROH}$ were highly correlated ( $\mathrm{r}=$ 0.69) (Fig. $1 \mathrm{C}$ ). Notably, extremely high correlations were found between the total lengths and total number for Small, Medium, and Large ROH ( $r=0.996$, 0.978, 0.963) (Supplement Figure S2).

\section{The consensus of $\mathrm{ROH}$ across the population}

To investigate the distribution of $\mathrm{ROH}$ enrichment within the population, we carried out an analysis of consensus $\mathrm{ROH}$ using PLINK with -homozyg-group option. We observed the highest frequency of consensus $\mathrm{ROH}$ (> $42 \%$ ) was located in the middle part of BTA6. Two $\mathrm{ROH}$ regions with frequencies of $34 \%$ and $25 \%$ were located on BTA7 and BTA11, respectively. We also detected 14,6 , and 1 consensus $\mathrm{ROH}$ (showing a rate of more than $25 \%$ ) on BTA6, BTA7, and BTA11 respectively. The genome-wide plot of the distribution of $\mathrm{ROH}$ enrichment was shown in Fig. 1 D. In the present study, we totally detected 42 regions with the $\mathrm{ROH}$ rate exceeding $20 \%$, accounting for 17 RefGenes based on UMD 3.1. These genes include DNAJC18, ECSCR, MATR3, PAIP2, SNHG4, SPATA24, TMEM173, UBE2D2, KED, DCAF16, LCORL, NCAPG, etc. 


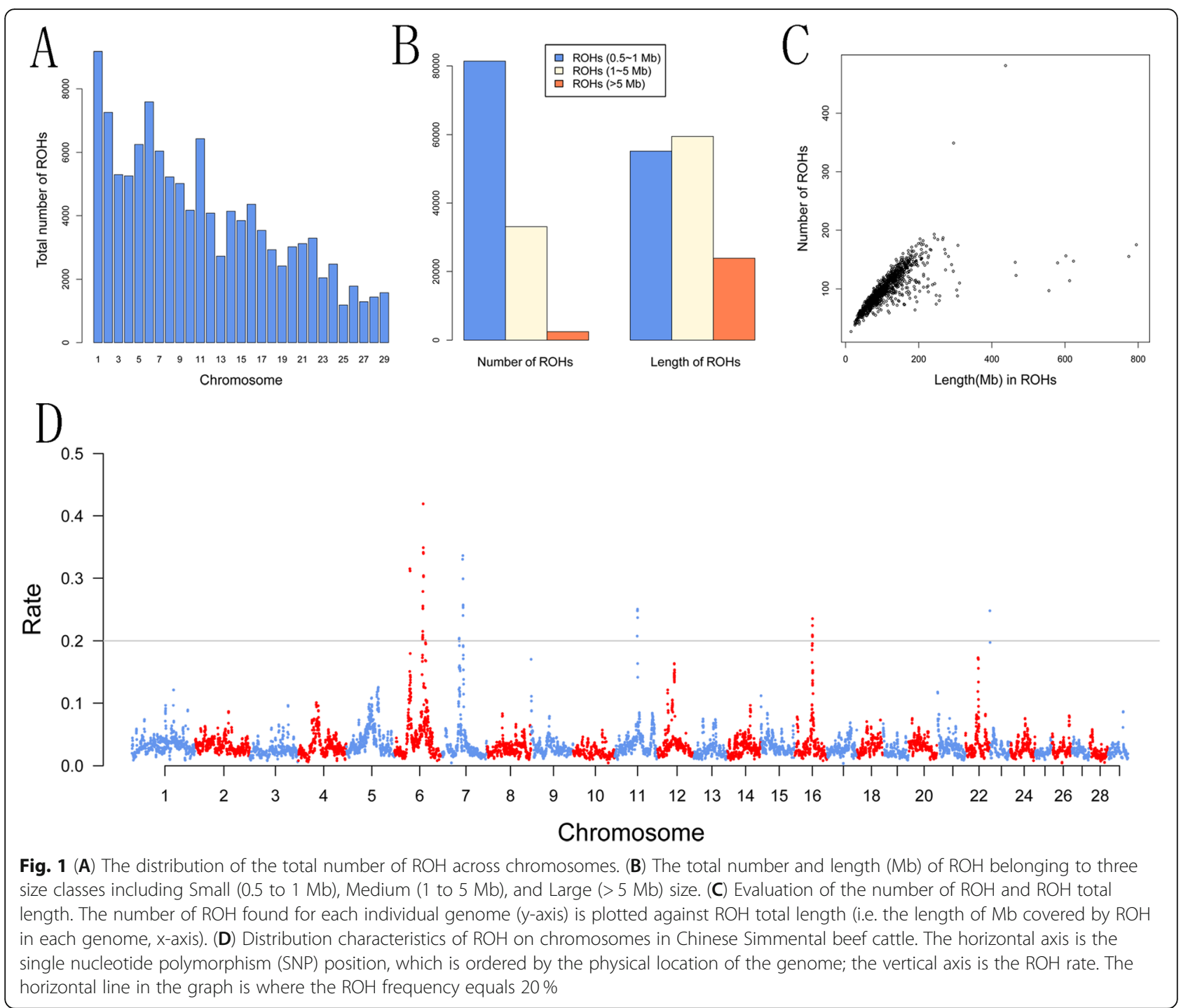

Moreover, we found several quantitative trait locus (QTLs) for weight gain and calving index overlapped with these regions based on the cattle QTLdb (https:// www.animalgenome.org/cgi-bin/QTLdb/BT/index).

\section{Evaluation of correlation between $\mathrm{ROH}$ and production traits}

To assess the association between homozygosity level and production traits, we performed the correlation analyses between the total length of $\mathrm{ROH}$ for each animal and adjusted phenotype including net meat weight (NMW), carcass weight (CW), average daily gain (ADG), and live weight (LW). Notably, we found the Pearson's correlation coefficient between the sum of $\mathrm{ROH}$ and four traits (NMW, CW, ADG, and LW) were 0.02, 0.04, 0.04 , and 0.05 (Fig. 2), respectively, whereas no significant difference was observed. Notably, we observed Pearson's correlation coefficient between small $\mathrm{ROH}$ and four traits (NMW, CW, ADG, and LW) were 0.13, 0.15, 0.14, 0.15 , while negative correlation coefficients were found when considering large $\mathrm{ROH}(-0.06,-0.054,-0.046$, -0.049) (Supplement Figure S3, S4 and S5).

\section{Identification of ROH between high and low groups using Fisher's exact test}

In this study, a total of 5,305 consentient $\mathrm{ROH}$ were detected across the genome in Chinese Simmental beef cattle (Supplement Table S2). The average length of overlapping $\mathrm{ROH}$ was $101.5 \mathrm{~kb}$, with an average of 26 SNPs. The largest region was $1,091 \mathrm{~kb}$ containing 20 SNPs, whereas the shortest one spanned $2.8 \mathrm{~kb}$ containing 5 SNPs.

The level of homozygosity may reflect potential variation in production traits among individuals. We 

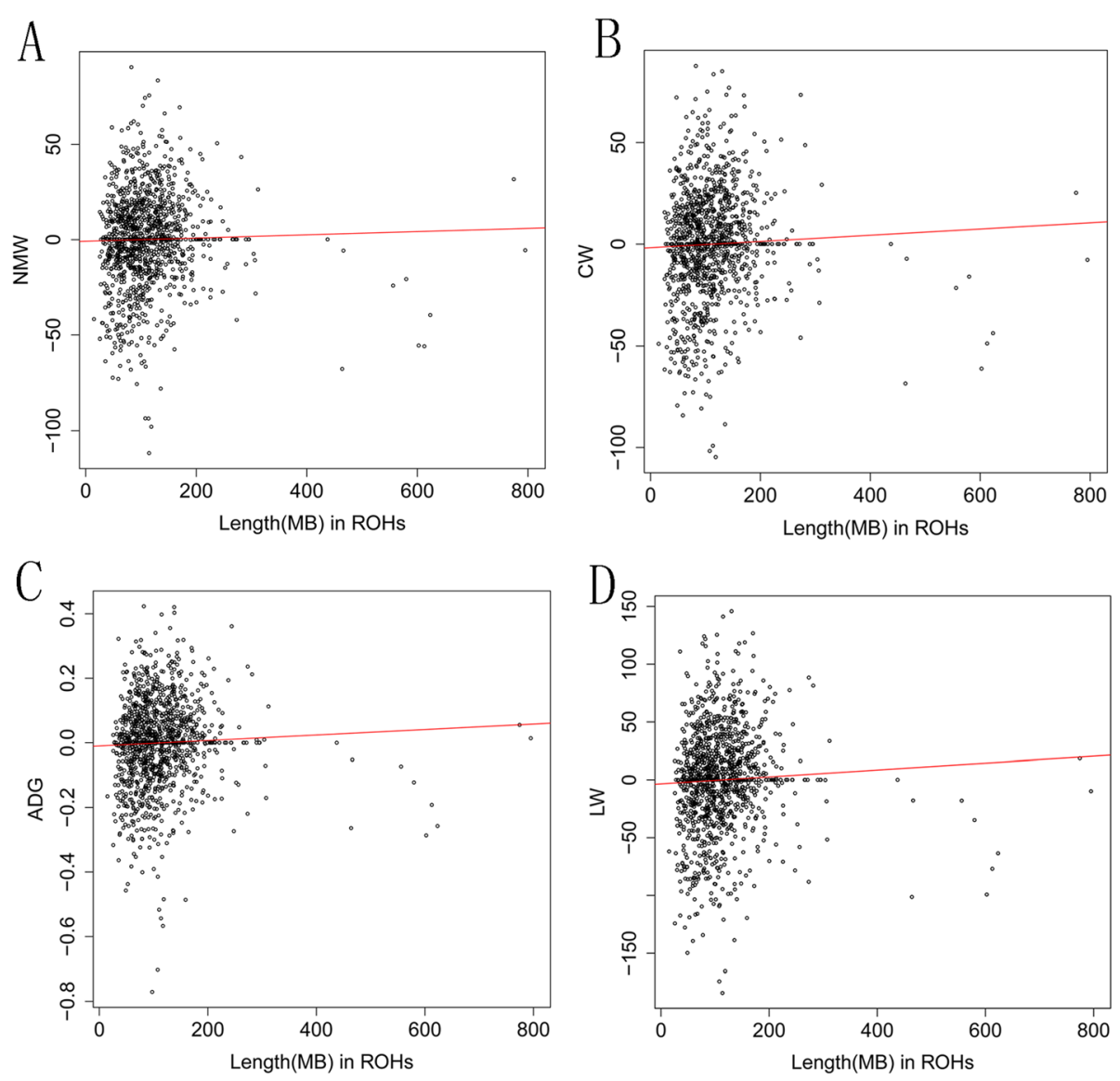

Fig. 2 Scatter plot of total homozygosity per individual against four corrected carcass traits (NMW, CW, ADG, LW). (A) Net meat weight (NMW), (B) Carcass weight (CW), (C) Average daily gain (ADG); (D) Live weight (LW)

evaluated the $\mathrm{ROH}$ patterns in terms of total length between the 300 high and low groups (Fig. 3). We found the total length of $\mathrm{ROH}$ was significantly different between high and low groups for production traits using Wilcoxon Rank Sum Tests (CW, P =1.85e-05; LW, P = 3.25e-06; NMW, $\mathrm{P}=1.56 \mathrm{e}-03 ; \quad$ ADG, $\quad \mathrm{P}=5.05 \mathrm{e}-05$ ). Then, the enrichments of consensus $\mathrm{ROH}$ were assessed using Fisher's exact test by comparing the top 300 high groups against the bottom 300 low groups. The consensus $\mathrm{ROH}$ were filtered and only those containing at least five SNPs were considered for subsequent analysis. Finally, 36, 35, 43, and 50 regions were obtained for NMW, CW, ADG, and LW.

\section{Association analysis of significant ROH}

To further validate the association between $\mathrm{ROH}$ and production traits, we performed association analysis using a mixed linear model as proposed by previous studies[13]. After the Fisher's exact tests, we found 36, 35,43 , and 50 candidate $\mathrm{ROH}$ regions for NMW, CW, ADG, and LW, respectively. Of these regions, 7 regions were significantly associated with production traits (P- value $<0.05)$. The summary statistics of candidate $\mathrm{ROH}$ regions and their candidate genes were listed in (Supplement Table S3).

After removing the redundant regions (as several regions were identified for two production traits), we obtained four unique candidate regions. Totally, we observed four genes related to production traits, which may play an important role in promoting growth and metabolic functions. These candidate genes were found in the $\mathrm{ROH}$ regions located on BTA1, BTA5, BTA6, and BTA9. Of these, we found one region located at (chr1: $95,450,372-95,517,810$ ) for average daily gain and live weight, which was largely overlapped with ECT2. Moreover, significant differences were observed for adjusted ADG $\left(\mathrm{P}=7.92 \times 10^{-3}\right)$ and LW $\left(\mathrm{P}=2.26 \times 10^{-3}\right)$ between individuals with $\mathrm{ROH}$ and those without $\mathrm{ROH}$ (Fig. 4 $\mathrm{A}$ and $\mathrm{B}$ ).

Consensus $\mathrm{ROH}$ that occur prevalently throughout the genome due to LD [20]. Our findings are consistent with a previous study by Purfield et al. which revealed that a majority of SNPs in the $\mathrm{ROH}$ region were in high LD with nearby SNPs [21]. Notably, we observed strong LD 

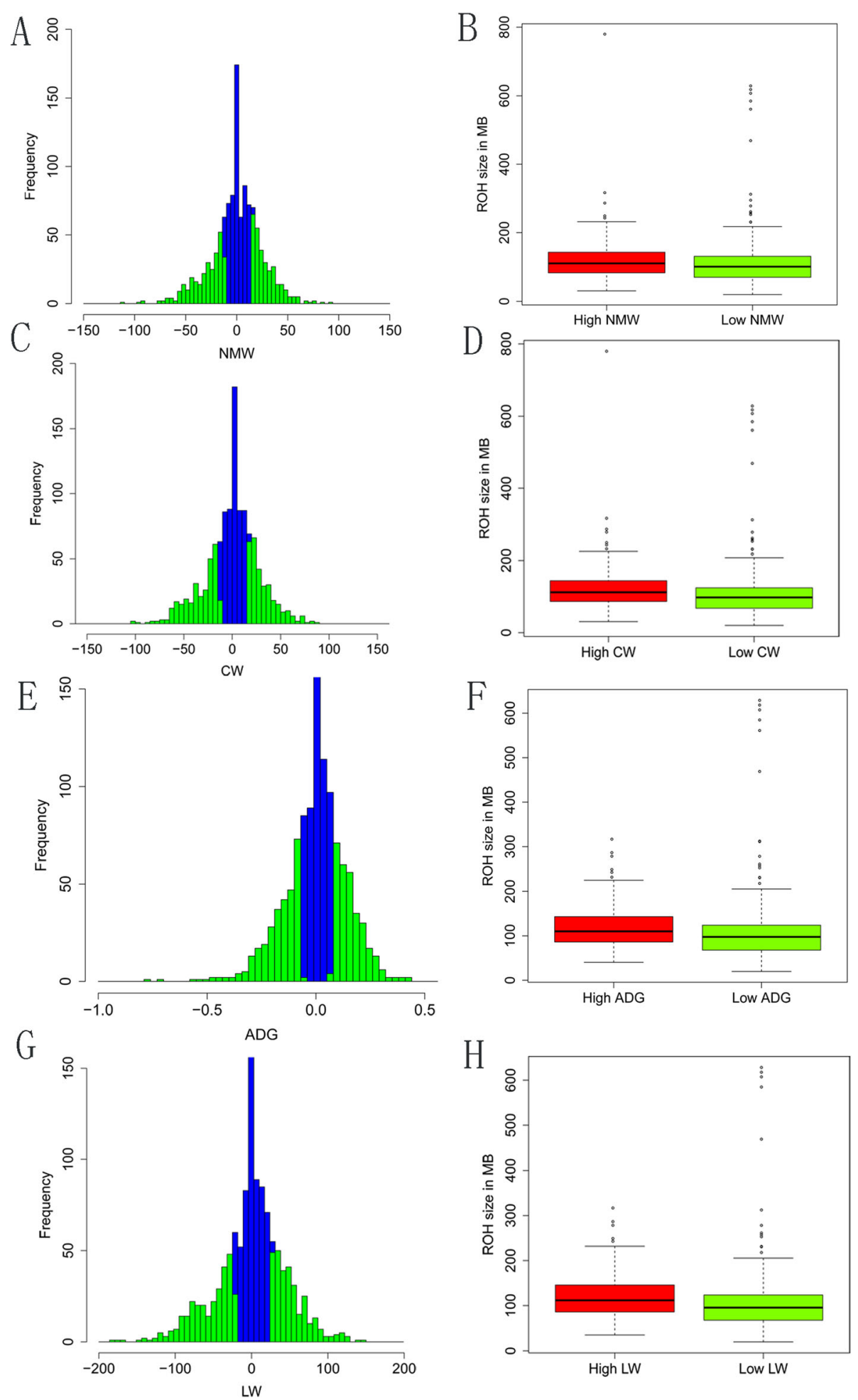

Fig. 3 Correlation between runs of homozygosity and four carcass traits (NMW, CW, ADG, LW). (A) Histogram showing the distribution of NMW for Chinese Simmental beef cattle. (B) Distribution of total homozygosity, calculated as the sum of all runs of homozygosity in the high group and low group for NMW. (C). Histogram showing the distribution of CW. (D). Distribution of total of runs of homozygosity in the high group and low for CW. (E). Histogram showing the distribution of ADG. (F). Distribution of total of runs of homozygosity in the high group and low group for ADG. (G). Histogram showing the distribution of LW. (H). Distribution of total of runs of homozygosity in the high group and low group for LW 


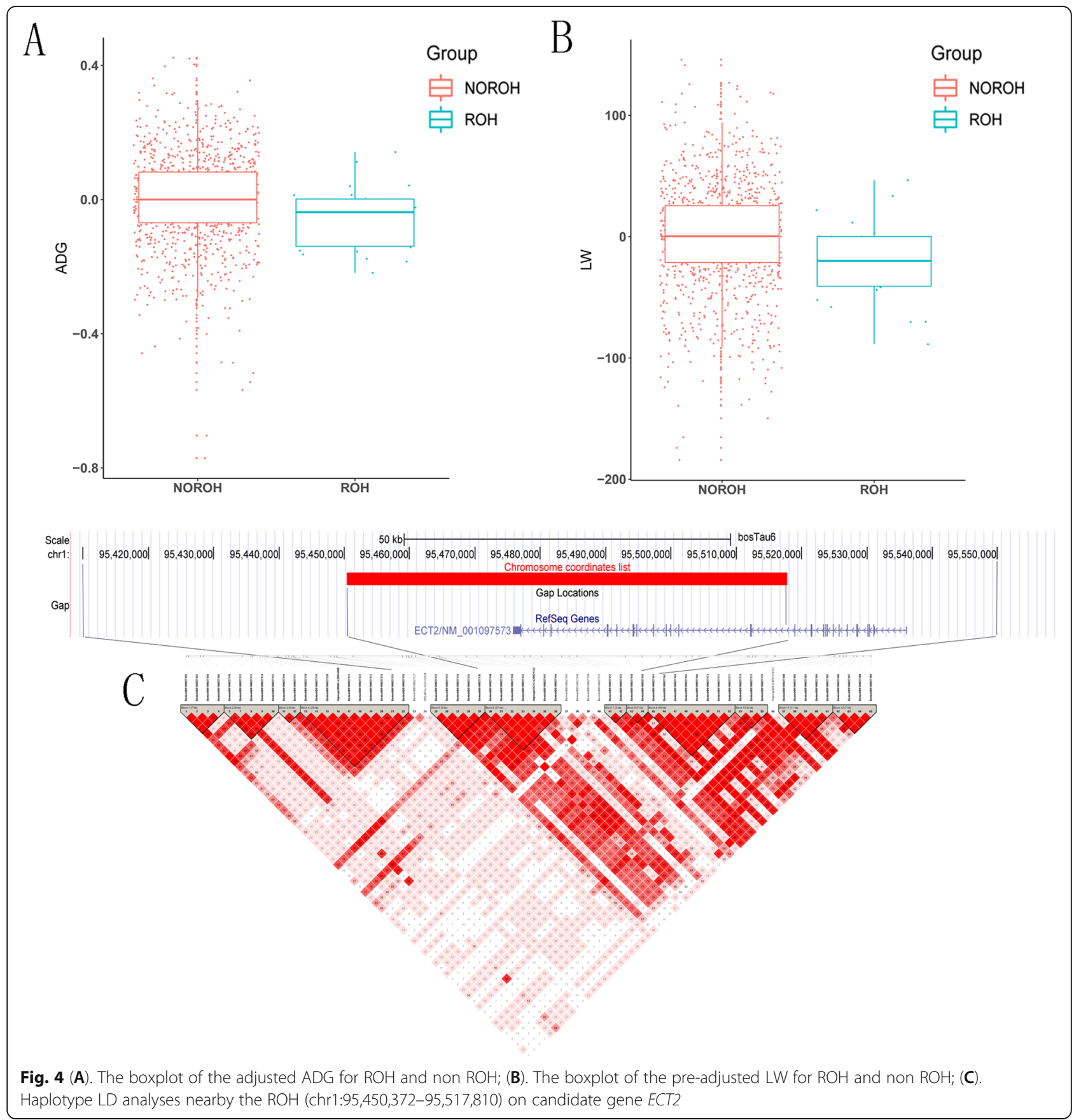

existed within the shared region between the $\mathrm{ROH}$ region and ECT2 (Fig. 4 C). We also observed one ROH region at BTA6 (chr6:67,192,462-67,290,024) with three genes (GABRA4, GABRB1, LOC536190) associated with CW $(\mathrm{P}=0.0110)$ and NMW $(\mathrm{P}=0.0052)$. However, no significant differences were observed for adjusted $\mathrm{CW}$ and NMW between individuals with $\mathrm{ROH}$ and those without $\mathrm{ROH}$. In addition, no gene was detected in two candidate regions at BTA5 and BTA9.

\section{Discussion}

The increasing use of key sires has been coupled with a drastic reduction in the generation interval for most cattle populations, representing both an opportunity and a challenge [22]. Artificial insemination may lead to the rapidly accumulating of homozygous segments. In the present study, we attempted to study the relationship between genome homozygous regions and production traits in beef cattle and explored the potential candidate 
genes. We evaluated the relationship between $\mathrm{ROH}$ and production traits in Chinese Simmental beef cattle using the BovineHD $770 \mathrm{~K}$ SNP arrays. Secondly, we divided our population into high and low trait groups to explore the enrichment of $\mathrm{ROH}$ fragments in production traits. Finally, we identified candidate $\mathrm{ROH}$ regions in the cattle genome and obtained several candidate genes that may affect production traits.

\section{Assessment of runs of homozygosity}

In this study, we characterized homozygosity regions for the first time in Chinese Simmental cattle using a high-density SNP array. We found a large proportion of small $\mathrm{ROH}(\sim 69.6 \%)$, which was similar to our previous report [23]. The high-density SNP array is more sensitive to the determination of small segments [24], while the low-density array may underestimate the small ROH. Many studies have reported that long $\mathrm{ROH}$ are mostly enriched in deleterious mutation regions, and inbreeding can increase the occurrence of rare recessive diseases that are homozygous for deleterious mutations [25]. Recent inbreeding is expected to be more harmful than ancient inbreeding because selection reduces the frequency of deleterious alleles over generations [26]. Our study revealed that the average number of short $\mathrm{ROH}$ segments per animal is large, which implied that most of the $\mathrm{ROH}$ segments in the studied population were derived from distant ancestors [19, 27].

\section{Identification of the high-frequency ROH among the population}

The selection of superior animals can yield large phenotypic changes and reshap the $\mathrm{ROH}$ patterns in specific regions across the genome. Previous studies have identified the most homozygous region ( $>45 \%$ of individuals with $\mathrm{ROH}$ ) on BTA6 within QTLs affecting milk fat and protein concentrations in local dairy cattle breeds [28]. Our study identified several high-frequency regions with consensus $\mathrm{ROH}$ which were overlapped with QTLs for important traits in cattle including body weight, strength and rump width, average daily gain, and shear force. For instance, we observed several peaks representing the high-frequency $\mathrm{ROH}$ region on BTA6 (Fig. 5 A), while most of the ROH were less than $400 \mathrm{~kb}$ (Fig. $5 \mathrm{~B}$ and C).

Notably, the small ROH are mainly selected and derived from ancient haplotypes [29]. Therefore, these $\mathrm{ROH}$ are likely to be undergoing positive selection for important traits and thus they were enriched with high frequency in the population. Remarkably, we observed a $1.2 \mathrm{Mb}$ region on BTA6 with three consensus $\mathrm{ROH}$, which was overlapped with genes (LAP3, NCAPG, and $L C O R L)$. Of those, we identified the largest $\mathrm{ROH}$ (425.68 kb) embedded with both NCAPG and LCORL.
These two genes have been indicated that were related to growth and carcass merit traits in many previous studies [30]. Moreover, many candidate variants were detected within or nearby NCAPG and LCORL using multiple strategies in various cattle breeds [31-35]. These two genes have also been implied to undergone positive selection in cattle and other farm animals [3641]. Remarkably, our study revealed a high LD pattern around this region which may indicate potential selection for favor allele and extend LD around them (Fig. 5D).

\section{Correlation between ROH characteristics and production traits}

To assess the effect of homozygosity on the production traits, we estimated the relationship between the total length of $\mathrm{ROH}$ for each individual and the production traits (NMW, CW, ADG, and LW). Our study revealed the total length of $\mathrm{ROH}$ in autosomes across individuals was weakly correlated with production traits, but not statistically significant.

Negative effects of inbreeding depression was observed on production traits in various dairy cattle [42-45]. Despite many previous studies suggested a negative association between bull fertility and the amount of homozygosity by assessing the total homozygous regions for each animal (sum of $\mathrm{ROH}$ ) versus sire conception rate records [13]. Conversely, an increase in performance also occurs for ancient inbreeding that arose from a distant common ancestor. For instance, Doekes et al. [26] reported an increase of $0.03 \mathrm{~kg}$ for ancient inbreeding in Dutch Holstein-Friesian dairy cattle. Moreover, a recent study suggested that a $1.33 \mathrm{~kg}$ gain for 305-day protein yield was found per $1 \%$ increase in short $\mathrm{ROH}$, representing the most distant pedigree age class in Canadian Holsteins [18].

Our study showed that the inbreeding coefficient of the Chinese Simmental beef cattle estimated from $\mathrm{ROH}$ is around 0.047 , suggesting the population has not experienced inbreeding. In our study, we observed an abundance of short $\mathrm{ROH}$ across the genome in the studied population. The short $\mathrm{ROH}$ derived from ancient haplotype which may have favorable inbreeding effects as compared with recent age of inbreeding. This finding may support the previous findings that ancient inbreeding occurred from a distant common ancestor is expected to display less unfavorable effects due to genetic purging $[16,26]$.

\section{Identification of candidate genes for production traits based on $\mathrm{ROH}$ analysis}

We compared the distribution of $\mathrm{ROHs}$ for high and low production trait groups (300 top and 300 bottom 
A

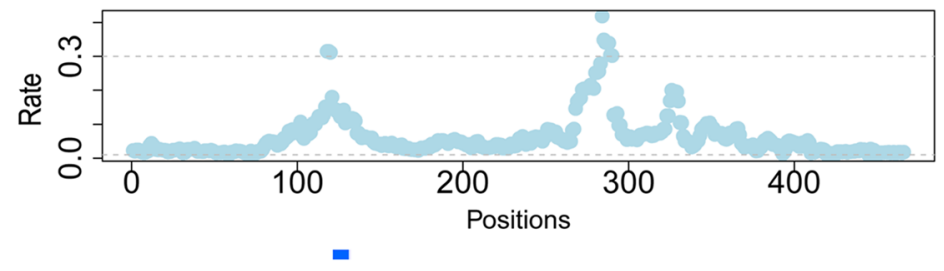

B

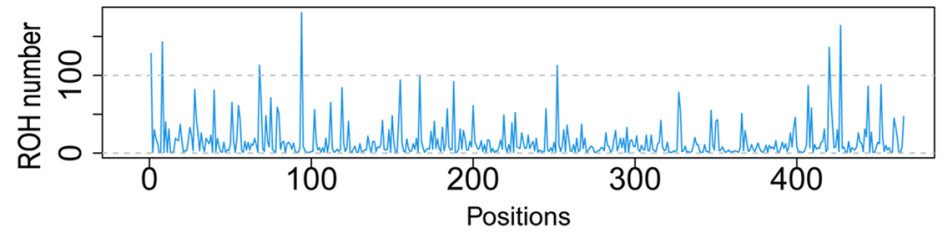

C
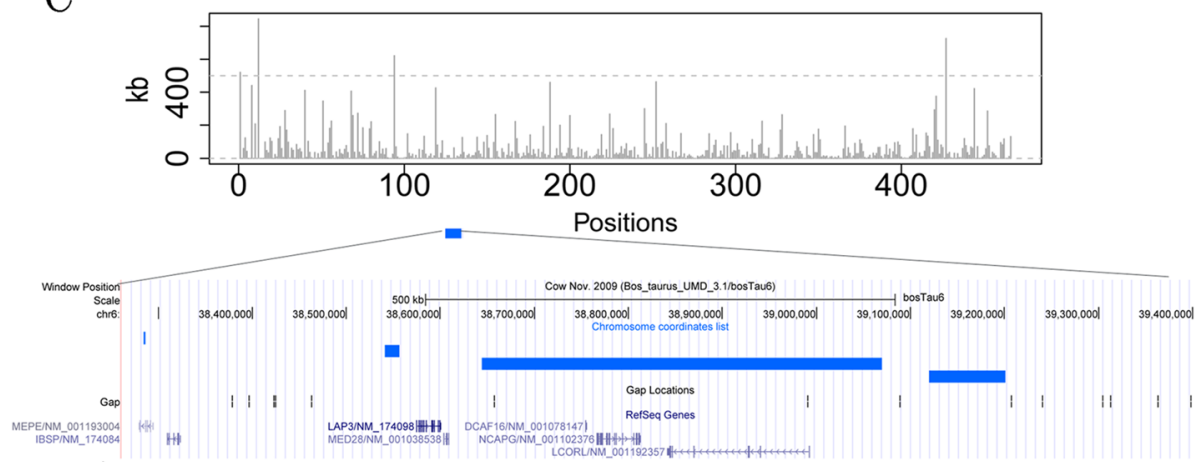

D

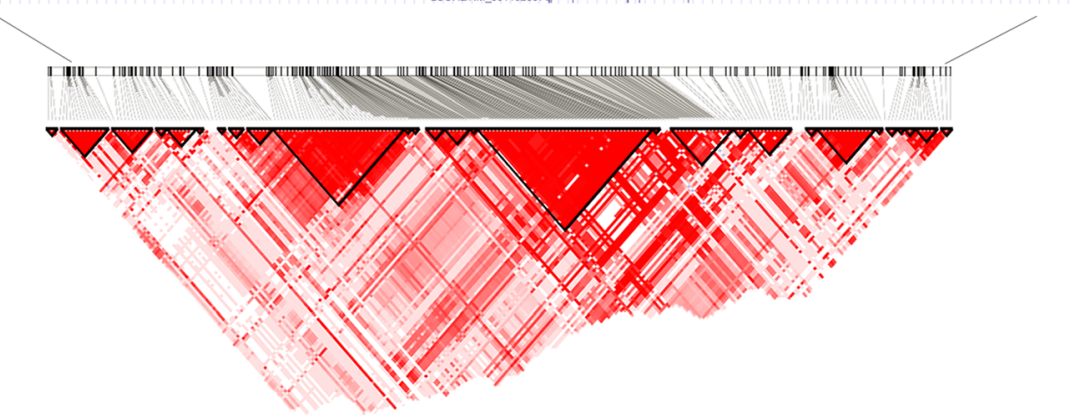

Fig. 5 (A). The rate of ROH plot at BTA6. (B). The number of ROH based on the region extracted from BTA6. (C). The length of ROH is based on the region extracted from BTA6. (D). Haplotype LD analyses nearby the $1.2 \mathrm{Mb}$ region with three consensus $\mathrm{ROH}$ were overlapped with three genes ( $L A P 3, N C A P G$, and $L C O L R$ )

individuals). Notably, a clear distribution difference was observed between the two groups in terms of the total length of $\mathrm{ROH}$, which implied the difference in the levels of homozygosity between the two groups. Notably, we identified 101 nonredundant regions associated with production traits using Fisher's exact test by comparing the top 300 high groups against the bottom 300 low groups. These regions account for a total of 120 candidate genes. Of those genes, several genes with candidate regions were observed that showing potential associations with reproduction traits as reported in previous publications. For instance, the region on BTA9 was identified for LW, NMW, ADG, and CW harboring three candidate genes (FAM229B, LAMA4, and TUBE1). $L A M A 4$ was localized and upregulated in damaged muscle fibers, and this gene appears to contribute to fiber survival in zebrafish [46]. Moreover, LAMA4-/mice were reported that exhibited reduced weight gain in response to both age and high-fat diet [47]. This gene has been indicated that closest to candidate QTL with pleiotropic effect on body composition [48]. In addition, several studies also suggested that LAMA4 was a candidate gene for meat quality $[49,50]$.

To further provide the association evidence, we performed an association test based on the identified $\mathrm{ROH}$ using a mixed linear model. Importantly, ECT2 
was previously identified for live weight and average daily gain. A recent study using weighted single-step association reported one region explains more than $0.5 \%$ of the additive genetic variance for residual intake and body weight gain overlapped with ECT2 in Nellore cattle [63].

Moreover, GABRA4 and GABRB1 belonged to gamma-aminobutyric acid (GABA)ergic Synapse, have been previously reported related to reproduction trait [51]. These genes involved in GABAergic signaling were included in the response to the organic cyclic compound biological process, which was related to conformation score [52]. GABA is synthesized from glutamate by the enzyme glutamic acid decarboxylase and was reported to play a role in controlling feeding behavior in ruminant animals. The GABAergic synapse pathway has also recently been associated with live weight in Simmental cattle [53]. In addition, GABRB1 and GABRA4 were reported as candidate genes affecting meat color traits in Nellore cattle [54].

\section{Conclusions}

We characterized the $\mathrm{ROH}$ and evaluated the association between ROH and production traits in Chinese Simmental beef cattle. Our study suggested that consensus ROHs derived from ancient haplotype may have a positive impact on production traits in beef cattle. Our findings provided a better understanding of the molecular basis underlying production traits from the aspect of homozygosity across cattle genomes.

\section{Methods}

\section{Ethics statement}

No ethics statement was required for the collection of genetic material. The data from animals included in this study were derived from previous analyses that obtained specific permissions.

\section{Phenotypic and genotypic data}

The dataset includes the phenotypes of 1,181 Chinese Simmental beef cattle born between 2008 and 2015 from Ulgai, Xilingol League, and Inner Mongolia, China. Average Daily Gain (ADG) was obtained with body weight gain divided by the number of fattening days. Carcass's merit traits were measured as described in our previous analysis $[31,55]$.

Samples were genotyped with Illumina BovineHD BeadChip and were processed with Genome Studio software. The individual call rate $>95 \%$ was kept, and SNP quality controls were carried out using PLINK v1.9 [56] based on minor allele frequency ( $>0.05$ ), the proportion of missing genotypes $(<0.05)$, Hardy-Weinberg equilibrium $(\mathrm{P}>10 \mathrm{e}-6)$. After quality control, 1181 individuals and 602,220 SNPs included in autosomes remained for subsequent analysis.

\section{Assessment of runs of homozygosity}

In this study, we used the PLINK v1.9 to detect ROH across cattle genomes [56]. The specific parameters were set as follows: 50 SNPs sliding window was used to detect homozygous segments in each individual, and the sliding window allowed no more than 1 heterozygote. Several parameters of defining $\mathrm{ROH}$ are involved: (i) the minimum length was $500 \mathrm{~kb}$; (ii) the proportion of homozygous overlap window was 0.05 ; (iii) the minimum number of consecutive SNPs included in an $\mathrm{ROH}$ was 100; (iv) the minimum SNP density was set to $50 \mathrm{~kb} / \mathrm{SNP}$; (v) the maximum gap between continuous homozygous SNPs was $100 \mathrm{~kb}$; (vi) a maximum of two SNPs with missing genotypes and up to one heterozygous genotype were allowed in an $\mathrm{ROH}$. $\mathrm{ROH}$ with different sizes were divided into three classes: (A) Small (500 kb to $1 \mathrm{Mb}$ ), (B) Medium (1 Mb to $5 \mathrm{Mb}$ ), and (C) Large $(>5 \mathrm{Mb})$, as described in a previous study [23].

\section{Correction test between $\mathrm{ROH}$ and production traits}

Association analysis was performed between $\mathrm{ROH}$ and four production traits (NMW, ADG, CW, and LW). Prior to inclusion in the analysis, all phenotypes were adjusted using the general linear model (farm, year and sex are the fixed effects and weight before fattening and fattening days were covariates). Then we considered the residuals as the adjusted phenotype for later analysis. In this study, we first estimated the relationship between the total length of $\mathrm{ROH}$ for each individual and the production traits (NMW, CW, ADG, and LW) using the Pearson correction test.

Then, we divided the population into two subgroups with extreme phenotypes: the high 300 group and the low 300 groups. Analysis of consensus $\mathrm{ROH}$ was performed using PLINK with -homozyg-group option. We defined consensus $\mathrm{ROH}$ as segments of overlapping $\mathrm{ROH}$ that had a minimum of five SNPs. Statistical significance for the proportion of individuals with $\mathrm{ROH}$ differed between the high and low groups were assessed using Fisher's exact test based on a $2 \times 2$ table for each $\mathrm{ROH}$. The UCSC Genome Browser (https://genome. ucsc.edu/) was used to retrieve genes within genomic regions of interest based on bovine genome assembly (UMD 3.1).

\section{Association analysis of significant ROH}

The set of significant $\mathrm{ROH}$ regions identified in the previous step was subsequently analyzed using the following linear mixed model: 


$$
\mathrm{y}=\mathrm{Xb}+\mathrm{Zu}+\mathrm{e}
$$

where $\mathbf{y}$ is the vector of phenotypes for the studied traits; b is the vector of fixed effects including $\mathrm{ROH}$, farm, year, sex, weight before fattening and fattening days. $\mathrm{ROH}$ that reach the significant level in the Fisher's exact tests, are regarded as a binary variable ( $\mathrm{ROH}$ presence/ROH absence). $\mathbf{X}$ and $\mathbf{Z}$ are the design matrices relating phenotypic traits to fixed and random effects, respectively; $\mathbf{u}$ is the vector of additive genetic effects and $\mathrm{e}$ is the vector of residual effects. The effects $\mathbf{u}$ and e were distributed as $\mathrm{u} \sim N\left(0, \mathbf{G} \sigma_{g}^{2}\right)$ and $\mathrm{e} \sim N\left(0, \mathbf{R} \sigma_{e}^{2}\right)$, where $\sigma_{g}^{2}$ and $\sigma_{e}^{2}$ are the additive genetic and residual variances, respectively, $\mathbf{G}$ is the additive genomic relationship matrix, which was constructed by synbreed packages based on SNPs $[57,58]$. $\mathbf{R}$ is an identity matrix. The associations between each $\mathrm{ROH}$ region and phenotypic traits were evaluated using linear mixed model analysis in ASReml v3.0 [59] with a statistical significance level (P-value $<0.05)$. Linkage disequilibrium between SNPs around the target regions was estimated and visualized using Haploview v4.3.

\section{Supplementary Information}

The online version contains supplementary material available at https://doi. org/10.1186/s12864-021-07992-6.

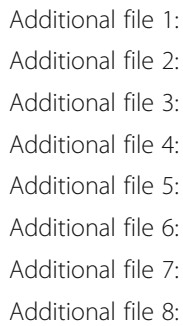

\section{Acknowledgements}

The authors would like to thank the staff at the cattle experimental unit in Beijing and Ulgai for caring for animals and collecting biological samples.

\section{Authors' contributions}

$L Y X, J Y L$, and GYZ conceived and designed the study. GYZ, ZZW, TLZ, and LX performed statistical analyses. GYZ and LYX wrote the paper. YQL, QHN, XZ, and $L X$ participated in data analyses. BZ, XG, LPZ, and HJG participated in the design of the study and contributed to the acquisition of data. All authors read, commented, and approved the final manuscript.

\section{Funding}

This study was supported by the Agricultural Science and Technology Innovation Program in the Chinese Academy of Agricultural Sciences (ASTIP-
IAS-TS-16 and ASTIP-IAS03), China Agriculture Research System of MOF and MARA and the National Beef Cattle Industrial Technology System (CARS-37). L.Y.X was supported by the Elite Youth Program in the Chinese Academy of Agricultural Sciences. The project was also partly supported by the Beijing City Board of Education Foundation (PXM2016_014207_000012) and the Science and Technology Project of Inner Mongolia Autonomous Region (2020GG0210) for the data analysis and interpretation of the study.

\section{Data Availability}

Datasets are available from the Dryad Digital Repository (doi:10.5061/ dryad.4qc06)

\section{Declarations}

Ethics approval and consent to participate

No ethics statement was required for the collection of genetic material. The data from animals included in this study were derived from previous analyses that obtained specific permissions.

\section{Consent for publication}

Not applicable.

\section{Competing interests}

The authors declare that they have no competing interests.

Received: 6 March 2021 Accepted: 7 September 2021

Published online: 21 September 2021

\section{References}

1. Ceballos FC, Joshi PK, Clark DW, Ramsay M, Wilson JF: Runs of homozygosity: windows into population history and trait architecture. Nat Rev Genet 2018, 19(4):220-234.

2. Peripolli E, Munari DP, Silva M, Lima ALF, Irgang R, Baldi F. Runs of homozygosity: current knowledge and applications in livestock. Anim Genet. 2017;48(3):255-71.

3. Leroy G. Inbreeding depression in livestock species: review and metaanalysis. Anim Genet. 2014;45(5):618-28.

4. Dorado J, Cid RM, Molina A, Hidalgo M, Ariza J, Moreno-Millán M, DemydaPeyrás S. Effect of inbreeding depression on bull sperm quality and field fertility. Reproduction, fertility, and development. 2017;29(4):712-20.

5. Cassell BG, Adamec $V$, Pearson RE. Maternal and fetal inbreeding depression for 70-day nonreturn and calving rate in Holsteins and Jerseys. J Dairy Sci. 2003;86(9):2977-83.

6. Adamec V, Cassell BG, Smith EP, Pearson RE. Effects of inbreeding in the dam on dystocia and stillbirths in US Holsteins. J Dairy Sci. 2006;89(1):30714.

7. Weigel K. Controlling inbreeding in modern breeding programs. Journal of Dairy Science. 2001;84:E177-84.

8. Weigeland K, Lin S. Controlling inbreeding by constraining the average relationship between parents of young bulls entering Al progeny test programs. Journal of Dairy Science. 2002;85(9):2376-83.

9. Lencz T, Lambert C, DeRosse P, Burdick KE, Morgan TV, Kane JM, Kucherlapati R, Malhotra AK. Runs of homozygosity reveal highly penetrant recessive loci in schizophrenia. Proc Natl Acad Sci U S A. 2007;104(50): 19942-7.

10. Yang HC, Chang LC, Liang YJ, Lin CH, Wang PL. A genome-wide homozygosity association study identifies runs of homozygosity associated with rheumatoid arthritis in the human major histocompatibility complex. PLoS One. 2012;7(4):e34840.

11. Johnson EC, Bjelland DW, Howrigan DP, Abdellaoui A, Breen G, Borglum A, Cichon S, Degenhardt F, Forstner AJ, Frank J, et al. No Reliable Association between Runs of Homozygosity and Schizophrenia in a Well-Powered Replication Study. PLoS Genet. 2016;12(10):e1006343.

12. Heron EA, Cormican P, Donohoe G, O'Neill FA, Kendler KS, Riley BP, Gill M, Corvin AP, Morris DW. No evidence that runs of homozygosity are associated with schizophrenia in an Irish genome-wide association dataset. Schizophrenia research. 2014;154(1-3):79-82.

13. Nani JP, Peñagaricano F. Whole-genome homozygosity mapping reveals candidate regions affecting bull fertility in US Holstein cattle. BMC Genomics. 2020;21(1):338. 
14. Martikainen K, Koivula M, Uimari P. Identification of runs of homozygosity affecting female fertility and milk production traits in Finnish Ayrshire cattle. Sci Rep. 2020;10(1):3804.

15. Broman KW, Weber JL: Long Homozygous Chromosomal Segments in Reference Families from the Centre d'Étude du Polymorphisme Humain. American Journal of Human Genetics 1999, 65(6):1493-1500.

16. Ferencakovic M, Solkner J, Kaps M, Curik I: Genome-wide mapping and estimation of inbreeding depression of semen quality traits in a cattle population. J Dairy Sci 2017, 100(6):4721-4730.

17. Doekes HP, Bijma P, Veerkamp RF, de Jong G, Wientjes YCJ, Windig JJ: Inbreeding depression across the genome of Dutch Holstein Friesian dairy cattle. Genet Sel Evol 2020, 52(1):64.

18. Makanjuola BO, Maltecca C, Miglior F, Schenkel FS, Baes CF: Effect of recent and ancient inbreeding on production and fertility traits in Canadian Holsteins. BMC Genomics 2020, 21(1):605.

19. Bosse M, Megens HJ, Madsen O, Paudel Y, Frantz LA, Schook LB, Crooijmans RP, Groenen MA: Regions of homozygosity in the porcine genome: consequence of demography and the recombination landscape. PLoS Genet 2012, 8(11):e1003100.

20. Jane G, Morton NE, Andrew C: Extended tracts of homozygosity in outbred human populations. Human Molecular Genetics 2006, 15(5):789-795.

21. Purfield DC, Berry DP, McParland S, Bradley DG: Runs of homozygosity and population history in cattle. BMC genetics 2012, 13(1):70.

22. Maltecca C, Tiezzi F, Cole JB, Baes C: Symposium review: Exploiting homozygosity in the era of genomics-Selection, inbreeding, and mating programs. J Dairy Sci 2020, 103(6):5302-5313.

23. Xu L, Zhao G, Yang L, Zhu B, Chen Y, Zhang L, Gao X, Gao H, Liu GE, Li J: Genomic Patterns of Homozygosity in Chinese Local Cattle. Scientific reports 2019, 9(1):16977.

24. Ferencakovic M, Solkner J, Curik I: Estimating autozygosity from highthroughput information: effects of SNP density and genotyping errors. Genet Sel Evol 2013, 45:42

25. Szpiech Zachary A, Xu J, Pemberton Trevor J, Peng W, Zöllner S, Rosenberg Noah A, Li Jun Z: Long Runs of Homozygosity Are Enriched for Deleterious Variation. 2013, 93(1):90-102.

26. Doekes HP, Veerkamp RF, Bijma P, de Jong G, Hiemstra SJ, Windig JJ: Inbreeding depression due to recent and ancient inbreeding in Dutch Holstein-Friesian dairy cattle. Genet Sel Evol 2019, 51(1):54.

27. Pemberton TJ, Absher D, Feldman MW, Myers RM, Rosenberg NA, Li JZ: Genomic patterns of homozygosity in worldwide human populations. Am J Hum Genet 2012, 91(2):275-292.

28. Mastrangelo S, Sardina MT, Tolone M, Di Gerlando R, Sutera AM, Fontanesi L, Portolano B: Genome-wide identification of runs of homozygosity islands and associated genes in local dairy cattle breeds. Animal: an international journal of animal bioscience 2018, 12(12):2480-2488.

29. Zhang Q, Guldbrandtsen B, Bosse M, Lund MS, Sahana G: Runs of homozygosity and distribution of functional variants in the cattle genome. BMC genomics 2015, 16(1):542.

30. Takasuga A: PLAG1 and NCAPG-LCORL in livestock. Animal science journal = Nihon chikusan Gakkaiho 2016, 87(2):159-167.

31. Zhang W, Li J, Guo Y, Zhang L, Xu L, Gao X, Zhu B, Gao H, Ni H, Chen Y: Multi-strategy genome-wide association studies identify the DCAF16-NCAPG region as a susceptibility locus for average daily gain in cattle. Sci Rep 2016, 6:38073.

32. Lindholm-Perry AK, Kuehn LA, Oliver WT, Sexten AK, Miles JR, Rempel LA, Cushman RA, Freetly HC: Adipose and muscle tissue gene expression of two genes (NCAPG and LCORL) located in a chromosomal region associated with cattle feed intake and gain. PLoS One 2013, 8(11):e80882

33. Widmann P, Reverter A, Fortes MR, Weikard R, Suhre K, Hammon H, Albrecht E, Kuehn C: A systems biology approach using metabolomic data reveals genes and pathways interacting to modulate divergent growth in cattle. BMC Genomics 2013, 14:798

34. Bouwman AC, Daetwyler HD, Chamberlain AJ, Ponce CH, Sargolzaei M, Schenkel FS, Sahana G, Govignon-Gion A, Boitard S, Dolezal M et al: Metaanalysis of genome-wide association studies for cattle stature identifies common genes that regulate body size in mammals. Nature genetics 2018, 50(3):362-367.

35. Xia J, Fan H, Chang T, Xu L, Zhang W, Song Y, Zhu B, Zhang L, Gao X, Chen $Y$ et al: Searching for new loci and candidate genes for economically important traits through gene-based association analysis of Simmental cattle. Sci Rep 2017, 7:42048.

36. Xu L, Bickhart DM, Cole JB, Schroeder SG, Song J, Tassell CP, Sonstegard TS, Liu GE: Genomic signatures reveal new evidences for selection of important traits in domestic cattle. Molecular biology and evolution 2015, 32(3):711725.

37. Mei C, Wang H, Liao Q, Wang L, Cheng G, Wang H, Zhao C, Zhao S, Song J, Guang X et al: Genetic Architecture and Selection of Chinese Cattle Revealed by Whole Genome Resequencing. Mol Biol Evol 2018, 35(3):688699.

38. Grilz-Seger G, Druml T, Neuditschko M, Mesarič M, Cotman M, Brem G: Analysis of $\mathrm{ROH}$ patterns in the Noriker horse breed reveals signatures of selection for coat color and body size. Anim Genet 2019, 50(4):334-346.

39. Druet T, Pérez-Pardal L, Charlier C, Gautier M: Identification of large selective sweeps associated with major genes in cattle. Anim Genet 2013, 44(6):758762.

40. Kijas JW: Haplotype-based analysis of selective sweeps in sheep. Genome 2014, 57(8):433-437.

41. ZHAO F-p, WEl C-h, Zhang L, LIU J-s, WANG G-k, Tao Z, DU L-x: A genome scan of recent positive selection signatures in three sheep populations. Journal of Integrative Agriculture 2016, 15(1):162-174.

42. Miglior F, Burnside EB, Kennedy BW: Production traits of Holstein cattle: estimation of nonadditive genetic variance components and inbreeding depression. J Dairy Sci 1995, 78(5):1174-1180.

43. Pryce JE, Haile-Mariam M, Goddard ME, Hayes BJ: Identification of genomic regions associated with inbreeding depression in Holstein and Jersey dairy cattle. Genet Sel Evol 2014, 46:71.

44. Mc Parland S, Kearney JF, Rath M, Berry DP: Inbreeding effects on milk production, calving performance, fertility, and conformation in Irish Holstein-Friesians. J Dairy Sci 2007, 90(9):4411-4419.

45. Croquet C, Mayeres P, Gillon A, Vanderick S, Gengler N: Inbreeding depression for global and partial economic indexes, production, type, and functional traits. J Dairy Sci 2006, 89(6):2257-2267.

46. Sztal TE, Sonntag C, Hall TE, Currie PD: Epistatic dissection of lamininreceptor interactions in dystrophic zebrafish muscle. Hum Mol Genet 2012, 21(21):4718-4731.

47. Vaicik MK, Thyboll Kortesmaa J, Movérare-Skrtic S, Kortesmaa J, Soininen R, Bergström G, Ohlsson C, Chong LY, Rozell B, Emont M et al: Laminin a4 deficient mice exhibit decreased capacity for adipose tissue expansion and weight gain. PLoS One 2014, 9(10):e109854.

48. Bolormaa S, Hayes BJ, van der Werf JH, Pethick D, Goddard ME, Daetwyler HD: Detailed phenotyping identifies genes with pleiotropic effects on body composition. BMC Genomics 2016, 17:224.

49. Xia J, Qi X, Wu Y, Zhu B, Xu L, Zhang L, Gao X, Chen Y, Li J, Gao H: Genome-wide association study identifies loci and candidate genes for meat quality traits in Simmental beef cattle. Mammalian genome: official journal of the International Mammalian Genome Society 2016, 27(5-6):246255.

50. Santos Silva DBD, Fonseca LFS, Magalhães AFB, Muniz MMM, Baldi F, Ferro JA, Chardulo LAL, Pinheiro DG, Albuquerque LG: Transcriptome profiling of muscle in Nelore cattle phenotypically divergent for the ribeye muscle area. Genomics 2020, 112(2):1257-1263.

51. Tahir MS, Porto-Neto LR, Gondro C, Shittu OB, Wockner K, Tan AWL, Smith HR, Gouveia GC, Kour J, Fortes MRS: Meta-Analysis of Heifer Traits Identified Reproductive Pathways in Bos indicus Cattle. Genes 2021, 12(5).

52. Pegolo S, Cecchinato A, Savoia S, Di Stasio L, Pauciullo A, Brugiapaglia A, Bittante G, Albera A: Genome-wide association and pathway analysis of carcass and meat quality traits in Piemontese young bulls. Animal: an international journal of animal bioscience 2020, 14(2):243-252.

53. Fan H, Wu Y, Zhou X, Xia J, Zhang W, Song Y, Liu F, Chen Y, Zhang L, Gao X et al: Pathway-Based Genome-Wide Association Studies for Two Meat Production Traits in Simmental Cattle. Scientific reports 2015, 5:18389.

54. Marin-Garzon NA, Magalhaes AFB, Mota LFM, Fonseca LFS, Chardulo LAL, Albuquerque LG: Genome-wide association study identified genomic regions and putative candidate genes affecting meat color traits in Nellore cattle. Meat science 2021, 171:108288.

55. Xu L, Gao N, Wang Z, Xu L, Liu Y, Chen Y, Xu L, Gao X, Zhang L, Gao H et al: Incorporating Genome Annotation Into Genomic Prediction for Carcass Traits in Chinese Simmental Beef Cattle. Front Genet 2020, 11:481. 
56. Chang CC, Chow CC, Tellier LC, Vattikuti S, Purcell SM, Lee JJ: Secondgeneration PLINK: rising to the challenge of larger and richer datasets. GigaScience 2015, 4:7.

57. Covarrubias-Pazaran G: Genome-Assisted Prediction of Quantitative Traits Using the R Package sommer. PLoS One 2016, 11(6):e0156744.

58. Wimmer V, Albrecht T, Auinger HJ, Schön CC: synbreed: a framework for the analysis of genomic prediction data using R. Bioinformatics 2012, 28(15): 2086-2087.

59. Gilmour AR, Gogel, B.J., Cullis, B.R., and Thompson, R: ASReml User Guide Release 3.0 VSN International Ltd, Hemel Hempstead, HP1 1ES, UK 2009

\section{Publisher's Note}

Springer Nature remains neutral with regard to jurisdictional claims in published maps and institutional affiliations.

Ready to submit your research? Choose BMC and benefit from:

- fast, convenient online submission

- thorough peer review by experienced researchers in your field

- rapid publication on acceptance

- support for research data, including large and complex data types

- gold Open Access which fosters wider collaboration and increased citations

- maximum visibility for your research: over $100 \mathrm{M}$ website views per year

At $\mathrm{BMC}$, research is always in progress.

Learn more biomedcentral.com/submissions 